\title{
Complementarity of Raman and Infrared Spectroscopy for Rapid Characterization of Fucoidan Extracts
}

\section{Signe Ptak}

University of Southern Denmark

\section{Lee Sanchez}

Texas A\&M University

\section{Xavier Frette}

University of Southern Denmark: Syddansk Universitet

Dmitry Kurouski ( $\nabla$ dkurouski@tamu.edu )

Texas A and M University: Texas A\&M University College Station https://orcid.org/0000-0002-60404213

\section{Research}

Keywords: Sulfated polysaccharides, Fucoidans, Raman spectroscopy, Infrared spectroscopy

Posted Date: October 27th, 2020

DOl: https://doi.org/10.21203/rs.3.rs-95623/v1

License: (c) (i) This work is licensed under a Creative Commons Attribution 4.0 International License. Read Full License

Version of Record: A version of this preprint was published at Plant Methods on December 1st, 2021. See the published version at https://doi.org/10.1186/s13007-021-00830-6. 


\title{
RESEARCH
}

\section{Complementarity of Raman and Infrared Spectroscopy for Rapid Characterization of Fucoidan Extracts}

\author{
Signe H. Ptak ${ }^{1}$, Lee Sanchez ${ }^{2}$, Xavier Fretté ${ }^{1}$ and Dmitry Kurouski ${ }^{*}$
}

\footnotetext{
${ }^{*}$ Correspondence: dkurouski@tamu.edu

${ }^{2}$ Department of Biochemistry and Biophysics, Texas A\&M University, College Station, United States Full list of author information is available at the end of the article
}

\begin{abstract}
Background: Fucoidans are sulfated polysaccharides from the cell-wall of brown algae. They have a wide range of applications in medicine, including regenerative medicine, ophthalmology, cancer, and autoimmune disease. Biological activity of fucoidans directly depends on their structure, which remains poorly understood. This is primarily because the polymeric nature of these molecules limits the use of nuclear magnetic resonance and mass spectrometry, classical tools of structural biology for their structural characterization. Raman and Infrared spectroscopies are non-invasive and non-destructive techniques that can be used to probe the structural organization of biological specimens. In this study, we investigate the potential of Raman and Infrared spectroscopy for structural analysis of several fucoidan extracts.
\end{abstract}

Results: Our results show that Infrared and Raman provide different but complimentary information about the structure of crude extracts of fucoidans, revealing the presence of minor impurities from co-extractants. We also found that at high extraction temperatures acidic conditions limit formation of melanoidins, while also yielding relatively high sulfate ester fucoidan. However, at high temperatures, water extraction may potentially result in formation of advanced glycation end products. Their presence could be problematic for fucoidan extracts intended for medicinal use, as advanced glycation end products have been linked to endocrine interruption mechanisms in vivo by crosslinking to and permanently altering extracellular matrix proteins.

Conclusion: Raman and Infrared can be used as complementary tools for rapid screening of crude fucoidan extracts, which can be a valuable tool for assessing impurities that remain after extraction.

Keywords: Sulfated polysaccharides; Fucoidans; Raman spectroscopy; Infrared spectroscopy

\section{Background}

Sulfated polysaccharides from the cell-wall of brown algae (fucoidans) are a diverse family of polydisperse hetero polymers with a wide range of applications in medicine, including regenerative medicine, ophthalmology, cancer[1, 2], and autoimmune disease[3]. Their structure-activity relationship has not been mapped in its entirety because of their heterogeneous nature and high variability due to seasonality, extraction method and the algae species used for fucoidan extraction. Fucoidan extraction typically involves soaking the seaweeds in aqueous or acidic solutions at ambient or high temperatures, while isolation is often performed by several 
precipitation steps involving calcium chloride and ethanol to desalt and remove low-molecular weight compounds. Other methods include the use of enzymes[4], microwave-assisted extraction[5, 6], and membrane filtration[7, 8]. Extraction and purification are closely linked to the structure and bioactivity of a fucoidan. Fucoidan may undergo structural changes during extraction, which affects their bioactivity. Microwave-assisted extraction provides rapid extraction of fucoidan, generating high yields and eliminating further extraction steps. The drawback of this method is thermal degradation of the backbone of the native fucoidan polymer: microwaving at temperatures below $100^{\circ} \mathrm{C}$ provides high yields and fucoidans high in fucose, but the fucose content decreases with increasing temperature, resulting in fucoidans with glucuronic acid as the main monosaccharide[6]. The fucoidan backbone may carry both carbohydrate (mostly L-fucopyranose and D-glucuronic acid) and non-carbohydrate substituents (sulfate and acetyl groups)[9]. Other monosaccharides may also be part of the backbone and/or part of the polymer branches in some algae species. Nearly all structural studies on fucoidan focus on characterizing the bioactivity by the degree of sulfation, but other studies have made it clear that the structure-function relationship is more complex. Additionally, many structural studies are barely comparable, as they vary in more than only their sulfation degree. Structural features like branching and molecular weight reportedly also affect the bioactivity. Cho et al, 2011 noted that a fucoidan fraction of 5-30 kDa exhibited a higher inhibitory effect on tumor growth compared to a fraction with a molecular weight of $>30 \mathrm{kDa}$, regardless of the higher molecular weight fucoidan having a higher sulfate content[2]. Sulfate esters do have a noticeable effect on several properties, including physico-chemical ones. Wei et al, 2019 found that decreasing the amount of ester sulfate groups in L. Japonica fucoidan increased aggregate formation, due to an abundance of inter-chain hydrogen bonds[10]. Such conformational changes are less studied, even though they may affect how the polymer interacts with active sites in vivo. One key factor is the presence (or absence) of side chains throughout the polymer, as they reduce the flexibility of the oligosaccharide backbone and stiffen the polymer. Increased stiffness may be favorable in some cases, as this forces the fucoidan polymer to adopt another conformation. One fucoidan polymer with several side chains was reportedly adopting a conformation recognized by certain receptor proteins[11]. Highly flexible, linear polymers, on the other hand, can axially rotate each bond in the polymer chain to fit the whole fucoidan molecule to a certain steric arrangement. This structural property enables the fucoidan to interact with positively charged amino acid residues of receptor proteins[12]. Having such massive impact on bioactivity, it is essential to analyze the fucoidan structure after extraction.

Structural analysis of crude extracts directly after extraction may reveal what fucoidan features (if any) are altered by the extraction method. Ideally, this should be a rapid analysis, performed in real-time. Infrared and Raman are versatile, nondestructive tools for the identification of biomolecules in plant cells and tissues. These techniques are highly advantageous during production processes, as they can be used with minimal preparation for in-line analysis. Using both Raman and FT-IR provides structural insight that would otherwise be unattainable from one technique 
alone. Bond vibrations with strong intensities in the IR spectra are typically weak contributors to Raman spectra and vice versa. For an IR transition, the vibrational motion is accompanied by a change in dipole moment, while it is the change in polarizability of the electron cloud within the molecule that lead to strong Raman bands[13]. This paper explores the complementarity of Raman and FT-IR structure analysis on fucoidan extracts.

\section{Results and discussion}

Size-exclusion chromatography

Table 1 shows the proposed size distribution of each fucoidan extract and the two structural references. Two acid extracts (AEs) show varying degrees of hydrolysis, with a main molecular weight of $1545 \mathrm{kDa}$ and $961 \mathrm{kDa}$ for the sulfuric acid and hydrochloric acid extract, respectively. The water extract (WE) contains the most diverse size composition, with a main molecular weight of $470 \mathrm{kDa}$. A massive polymer with a molecular weight above $50000 \mathrm{kDa}$ accounts for $16 \%$ of the $\mathrm{WE}$, which greatly exceeds the average weight of fucoidan. This suggests that polymerization or the creation of another compound has taken place during fucoidan extraction.

Elemental analysis

Table 1 shows the sulfate ester and nitrogen content of each fucoidan extract and reference. The nitrogen content is typically quite low for brown algae, as they do not contain significant amounts of protein.

\section{Raman and Infrared on references and extracts}

In the Raman and IR spectra collected from the fucoidan extracts (see Figure 1, vibrational bands that can be assigned to carbohydrates, melanoidins and amides where observed. In the IR spectra, bands belonging to carbohydrates, melanoidins, sulfate esters, and amides (Table 2) were seen. The peak intensities among the extracts differ. This may be a result of pigmented compounds formed during microwave extraction. The colourants may absorb a significant fraction of laser light.

Infrared analysis of fucoidan extracts

A vibrational band at $830 \mathrm{~cm}^{-1}$ was observed in the IR spectrum of all fucoidan extracts and in the fucoidan standard. This vibrational band can be assigned to $\alpha$ pyranose[17]. Since only one band is present in this linkage region, it is highly likely that this fucoidan has a simple, linear structure. From literature searches on the structural features of Fucus vesiculosus fucoidan, it can be seen that the backbone contains alternating $\alpha(1 \rightarrow 3)$ and $\alpha(1 \rightarrow 4)$ linkages of L-fucopyranose units[29]. This indeed confirms that the polymer has a simple, linear structure. Laminarin functions as a beta-glucan storage polymer in brown algae, which explains why the $830 \mathrm{~cm}^{-1}$ band for $\alpha$-pyranose is absent in the laminarin spectra. This region (the pyranose region) has previously been used to assign the positions of the sulfate ester groups (-OSO3-) on the monosaccharide units[30]. Extracting such structural information from the IR alone can be a powerful tool when characterizing the structure and potential function of a fucoidan extract. The -OSO3- position influence polymer properties, and axial positions greatly determine the conformational flexibility of the fucoidan polymer[31]. Two bands in the pyranose region can be used to 
Table 1 Chemical characterization of fucoidan samples and references. Size distribution and the intensity of each polymer weight in RID, and the results of the elemental analysis on the sulfate ester content (calculated from S\%) and the nitrogen content of each extract and reference

\begin{tabular}{|c|c|c|c|c|}
\hline Sample & $\mathrm{Mw}[\mathrm{kDa}]$ & Mw Relative intensity [\%] & Sulfate ester content [\%] & Nitrogen content \\
\hline Fucoidan reference & $\begin{array}{c}1884 \\
809 \\
611 \\
4\end{array}$ & $\begin{array}{c}91.15 \\
2.8 \\
4.93 \\
1.12\end{array}$ & $31.56 \pm 2.44$ & $0.02 \pm 0.02$ \\
\hline Laminarin reference & $\begin{array}{c}5400 \\
3155 \\
1010 \\
598 \\
12 \\
7\end{array}$ & $\begin{array}{c}3.29 \\
2.4 \\
9.8 \\
0.62 \\
1.21 \\
82.68\end{array}$ & $10.92 \pm 2.44$ & $0.16 \pm 0.02$ \\
\hline $\mathrm{H}_{2} \mathrm{O}$ extract & $\begin{array}{c}52658 \\
3260 \\
470 \\
340 \\
9 \\
7 \\
5 \\
4\end{array}$ & $\begin{array}{c}16.12 \\
26.66 \\
34.58 \\
8.78 \\
3.34 \\
5.84 \\
3.42 \\
1.27\end{array}$ & $16.2 \pm 2.44$ & $0.23 \pm 0.02$ \\
\hline $\mathrm{H}_{2} \mathrm{SO}_{4}$ extract & $\begin{array}{c}1545 \\
611 \\
8 \\
7 \\
5\end{array}$ & $\begin{array}{c}88.48 \\
5.34 \\
2.31 \\
3.15 \\
0.72\end{array}$ & $17.85 \pm 2.44$ & $0.12 \pm 0.22$ \\
\hline $\mathrm{HCl}$ extract & $\begin{array}{c}961 \\
547 \\
8 \\
7 \\
5\end{array}$ & $\begin{array}{c}84.67 \\
7.34 \\
4.31 \\
3.09 \\
0.59\end{array}$ & $20.93 \pm 2.44$ & $0.16 \pm 0.02$ \\
\hline
\end{tabular}


Table 2 Vibrational bands in fucoidan and laminarin

\begin{tabular}{|c|c|c|c|}
\hline RS & IR & Vibrational Mode & Assignment \\
\hline 428 & & $\mathrm{C}-\mathrm{O}-\mathrm{C}+\mathrm{C}-\mathrm{C}-\mathrm{C}$ ring deformation & Carbohydrate[14] \\
\hline 486 & & & \\
\hline 571 & & $\delta(\mathrm{C}-\mathrm{C}-\mathrm{O})+\tau(\mathrm{C}-\mathrm{O})$ & Carbohydrate[14] \\
\hline 592 & & & \\
\hline $\begin{array}{l}608 \\
668\end{array}$ & & $\delta(\mathrm{C}-\mathrm{C}-\mathrm{O})$ & Carbohydrate[14] \\
\hline 726 & & $\delta(\mathrm{C}-\mathrm{C}-\mathrm{O})$ & Carbohydrate[14] \\
\hline 826 & & C-O-S stretching, $\alpha-1.3$ bond & Fucoidan \\
\hline & 830 & C-O-S stretching & $\begin{array}{l}\alpha \text {-pyranose[15], C-O-S of } \\
\text { eq. sulfate ester on C-2[16] }\end{array}$ \\
\hline 888 & & $\delta(\mathrm{C}-\mathrm{C}-\mathrm{H})+\delta(\mathrm{C}-\mathrm{O}-\mathrm{C})$ & Carbohydrate[17] \\
\hline & 893 & C-O-S stretching & $\begin{array}{l}\text { equatorial sulfate ester of a } \\
\text { pyranoid sugar[18, 19] }\end{array}$ \\
\hline & 965 & $\nu(\mathrm{C}-\mathrm{O})$ in $\mathrm{C}-\mathrm{O}-\mathrm{C}$ linkage, $\beta(\mathrm{C}-\mathrm{O}-\mathrm{H})$ & Carbohydrate[13] \\
\hline 1004 & & Aromatic ring breathing & $\begin{array}{l}\text { Aromatic compound from } \\
\text { Maillard reaction }\end{array}$ \\
\hline & 1014 & $\beta(\mathrm{C}-\mathrm{O}-\mathrm{H})+\nu(\mathrm{C}-\mathrm{C}), \mathrm{C}-\mathrm{O}-\mathrm{S}$ Stretching & Trisaccharide[13], fucoidan \\
\hline $\begin{array}{l}1054 \\
1080\end{array}$ & 1080 & $\begin{array}{l}\nu(\mathrm{C}-\mathrm{O})+\nu(\mathrm{C}-\mathrm{C})+\delta(\mathrm{C}-\mathrm{O}-\mathrm{H}) \\
\nu(\mathrm{C}-\mathrm{O})+\nu(\mathrm{C}-\mathrm{C})+\delta(\mathrm{C}-\mathrm{O}-\mathrm{H})\end{array}$ & $\begin{array}{l}\text { Carbohydrate[14] } \\
\text { Carbohydrate[13 14] }\end{array}$ \\
\hline 1119 & 1080 & $\nu(\mathrm{C}-\mathrm{O})+\nu(\mathrm{C}-\mathrm{C})+\delta(\mathrm{C}-\mathrm{O}-\mathrm{H})$ & $\begin{array}{l}\text { Carbohydrate }[13,14] \\
\text { Carbohydrate[14] }\end{array}$ \\
\hline & 1129 & $\mathrm{C}-\mathrm{O}-\mathrm{C}+\mathrm{C}-\mathrm{O}-\mathrm{S}$ stretching hfill & Fucoidan \\
\hline 1148 & & $\begin{array}{l}\nu(\mathrm{C}-\mathrm{O}-\mathrm{C})+\nu(\mathrm{C}-\mathrm{C}) \text { in glycosidic linkages, } \\
\text { asymmetric ring breathing }\end{array}$ & Carbohydrate[13] \\
\hline & 1165 & $\nu(\mathrm{C}-\mathrm{O})$ & Glucose[13] \\
\hline 1203 & & $\nu(\mathrm{C}-\mathrm{C})+\nu(\mathrm{C}-\mathrm{O})$ & Carbohydrate[14] \\
\hline & 1224 & S-O stretching & Sulfate ester[17] \\
\hline & 1250 & S-O stretching & Sulfate ester shoulder \\
\hline 1262 & & $\delta(\mathrm{C}-\mathrm{C}-\mathrm{H})+\delta(\mathrm{C}-\mathrm{C}-\mathrm{H})+\delta(\mathrm{C}-\mathrm{O}-\mathrm{H})$ & Carbohydrate[14] \\
\hline 1335 & & $\nu(\mathrm{C}-\mathrm{O})+\delta(\mathrm{C}-\mathrm{O}-\mathrm{H}), \delta(\mathrm{C}-\mathrm{H})$ & $\begin{array}{l}\text { Carbohydrate[14], } \\
\text { Alginate[20] }\end{array}$ \\
\hline 1366 & & $\delta(\mathrm{C}-\mathrm{H})$ stretch & MG alginate[20] \\
\hline & 1384 & $\mathrm{CH}_{3}$ bending, symmetric & Carbohydrate[18] \\
\hline & 1420 & $\mathrm{C}-\mathrm{H}$ deformation & Melanoidin \\
\hline & 1437 & $\mathrm{O}-\mathrm{H}$ rocking & Monosaccharide \\
\hline 1456 & & $\begin{array}{l}\delta(\mathrm{C}-\mathrm{H})+\delta\left(\mathrm{CH}_{2}\right)+\delta(\mathrm{C}-\mathrm{O}-\mathrm{H}), \mathrm{CH}, \mathrm{CH}_{2} \\
\text { (in plane })+\mathrm{C}-\mathrm{O}-\mathrm{H} \text { deformations }+ \text { asymm. } \\
\text { COO- }\end{array}$ & $\begin{array}{l}\text { Carbohydrate[14], } \\
\text { alginate[20] }\end{array}$ \\
\hline 1529 & & $-\mathrm{C}=\mathrm{C}-($ in plane $)+$ vasym $\mathrm{COO}-$ & $\begin{array}{l}\text { Carotenoids[21], } \\
\text { alginate[20] }\end{array}$ \\
\hline & 1538 & $\nu(\mathrm{O}-\mathrm{C}-\mathrm{N})$ & Amide II[22] \\
\hline & 1600 & $\delta(\mathrm{C}-\mathrm{C}-\mathrm{H})+\mathrm{v}(\mathrm{C}=\mathrm{C})$ & Amide[23], Melanoidin[24] \\
\hline 1614 & & $\nu$ asym COO- & Alginate[20] \\
\hline 1627 & & $\nu(\mathrm{C}-\mathrm{C})+\mathrm{v}(\mathrm{C}=\mathrm{O})$ & Amide[25], Melanoidin \\
\hline & 1634 & $\nu(\mathrm{C}=\mathrm{O})+\nu(\mathrm{C}=\mathrm{C})+\nu(\mathrm{C}=\mathrm{N})$ & $\begin{array}{l}\text { Amide I[23], Melanoidin[24], } \\
\text { unhydrated } \beta \text {-sheets }[26,27]\end{array}$ \\
\hline 1664 & & $\nu(\mathrm{C}=\mathrm{O})$ stretching & Acetylamide[28] \\
\hline & 2853 & $\nu\left(\mathrm{CH}_{3}\right)$ stretch, symmetric & \\
\hline & 2925 & $\mathrm{v}\left(\mathrm{CH}_{2}\right)$ stretch, symmetric & Carbohydrate[22] \\
\hline & 2999 & $\mathrm{C}-\mathrm{H}$ stretching & Carbohydrate[18] \\
\hline & 3400 & $\mathrm{O}-\mathrm{H}$ stretching & Carbohydrate[15] \\
\hline
\end{tabular}




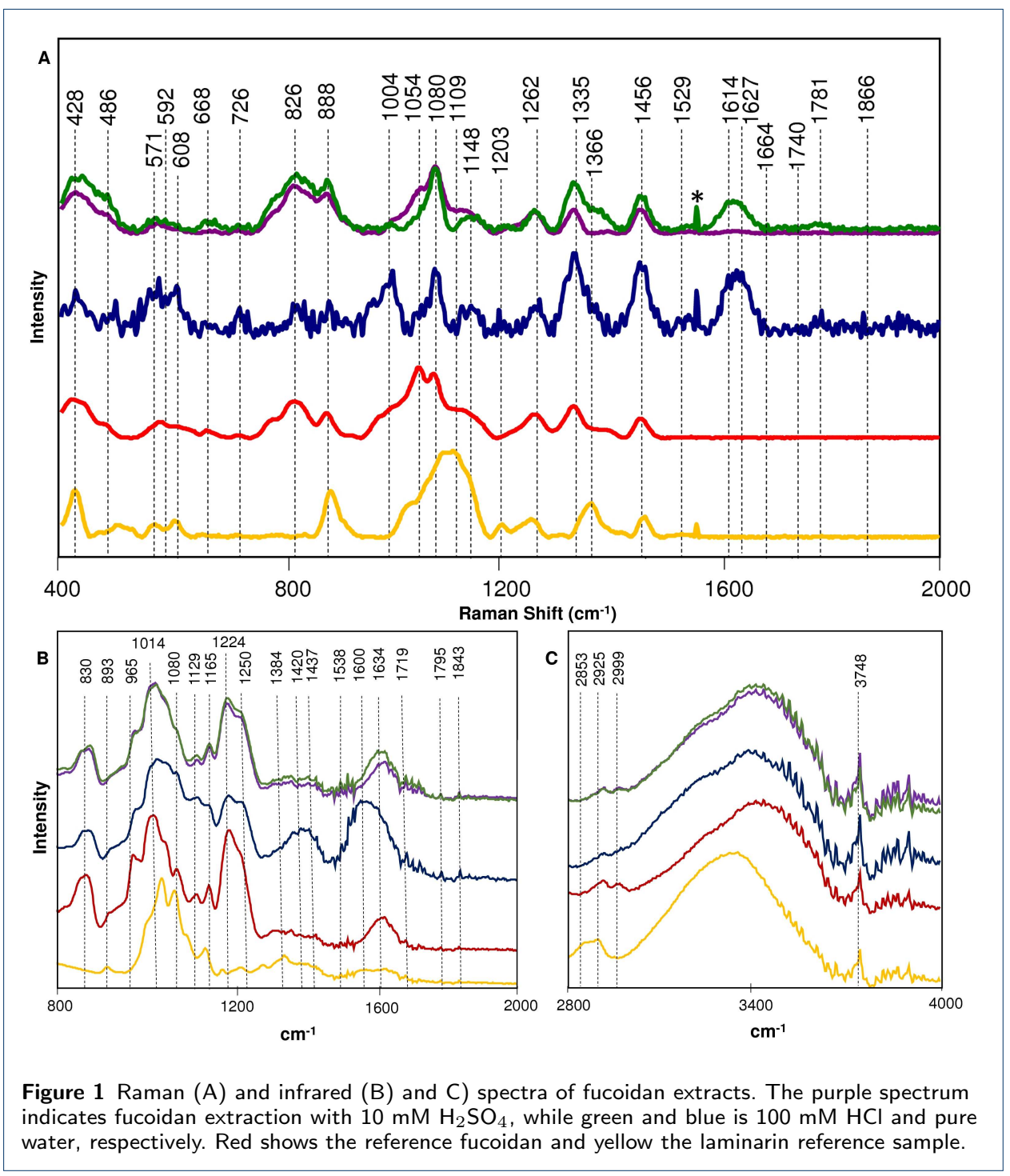

uncover the -OSO3- substitution pattern; a strong band at $844 \mathrm{~cm}^{-1}$ denotes axial position, while a shoulder band at $820 \mathrm{~cm}^{-1}$ shows an equatorial substitution[30]. These bands can also be assigned to the C-O-S, C-O, C-C and S-O vibrations[32], which makes unambiguous assignment of these bands challenging.

From the recorded infrared spectra, vibrational bands for sulphated polysaccharides were observed at $830 \mathrm{~cm}^{-1}, 893 \mathrm{~cm}^{-1}, 1014 \mathrm{~cm}^{-1}$, and $1129 \mathrm{~cm}^{-1}$. Although the bands seem to shift somewhat depending on the extraction method, they can be assigned to the C-O-S vibration of a -OSO3-. The $830 \mathrm{~cm}^{-1}$ band was found to be a distinguishing feature of fucoidan in the spectra as it shows 1) the molecule is sulfated, as given by the C-O-S vibration from -OSO3- (possibly on C-235) and 2) the joined monosaccharides have $\alpha$-conformation. Although we did not observe a band for an equatorial substitution pattern at $820 \mathrm{~cm}^{-1}$, we observed a band at 893 $\mathrm{cm}^{-1}$ in IR, which can be assigned to the general C-O-S stretching of an equatorial -OSO3- of a pyranoid sugar[18]. A C-O-S band at $893 \mathrm{~cm}^{-1}$ was also observed for 
laminarin and the elemental analysis confirms that the laminarin standard is indeed sulfated, albeit to a lesser degree than the fucoidan extracts and the fucoidan standard in this study. The band at $1224 \mathrm{~cm}^{-1}$ and the shoulder at $1250 \mathrm{~cm}^{-1}$ is often used for detection of sulfated polysaccharides and they can be assigned to S-O stretches from sulfate esters. These bands are seen in all the IR spectra collected from fucoidan, while they are absent in the spectra collected from laminarin. These bands are stronger in the spectra of AEs and in the Sigma standard, suggesting that at high extraction temperatures, the amount of sulphated fucoidan is larger in acid-based extracts. The peak intensities and shape of the $1014 \mathrm{~cm}^{-1}$ and the $1224 \mathrm{~cm}^{-1}$ wavebands in the WE also suggests that some of the fucose has been lost during extraction. Lowering the $\mathrm{pH}$ may preserve the sulfate ester groups at elevated extraction temperatures. This preserving effect may be due to the mitigation of the Maillard reaction (reaction between a reducing sugar, such as glucose, and the carbonyl group of free amino acid), as lowering the $\mathrm{pH}$ reduces the reaction rate. Although the calculated sulfate ester content in laminarin may be from not dialyzing the extract after extraction, the absence of the $1224 \mathrm{~cm}^{-1}$ and the 1250 $\mathrm{cm}^{-1}$ shoulder bands from the laminarin spectra may suggest that, as the degree of sulfation increases, not only does the intensity of the sulfation bands increase, more sulfation bands can be seen in the IR spectra.

Assignment of the bands at $1600 \mathrm{~cm}^{-1}$ and $1634 \mathrm{~cm}^{-1}$ presented some difficulties, but literature searches combined with the results from both the elemental analysis and by size-exclusion chromatographhy resulted in the tentative assignment of these bands to melanoidins. In IR, this region may denote $\mathrm{C}=\mathrm{C}, \mathrm{C}=\mathrm{O}$, and $\alpha, \beta$ diketones[24]. We propose that melanoidins were formed during extraction as a result from the Maillard reaction. The intensity of the $1600 \mathrm{~cm}^{-1}$ and $1634 \mathrm{~cm}^{-1}$ bands are higher in the $\mathrm{WE}$, which we attribute to the $\mathrm{pH}$ of the extraction solvent. The AEs had lower $\mathrm{pH}$ during extraction, which may mitigate the Maillard reaction and result in less Maillard reaction products.

The wavebands $1420 \mathrm{~cm}^{-1}$ and $1634 \mathrm{~cm}^{-1}$ are also highly solvent (or $\mathrm{pH}$ ) dependent, as the intensity is much higher in the WE. The $1420 \mathrm{~cm}^{-1}$ waveband can be assigned to -C-H deformation, while definite assignment of the $1634 \mathrm{~cm}^{-1}$ waveband is more challenging. This band is often assigned to the amide I stretch $\nu(\mathrm{C}=\mathrm{O})$, but it may also denote a $\beta$-sheet structure for protein and to $\mathrm{C}=\mathrm{C}$ stretching and even to $\mathrm{C}=\mathrm{N}$ stretching vibrations for melanoidins [33, 34]. Based on the IR spectra and the elemental analysis, we propose that the AEs contain low amounts of protein, while the WE likely contains both a small amount of protein and the brown, nitrogenous, high molecular weight polymers, melanoidins. Structural information on melanoidins is limited due to their high structural complexity and diversity, but they are widely found in processed foods. Two minor peaks at $2925 \mathrm{~cm}^{-1}$ and $2994 \mathrm{~cm}^{-1}$ were also observed. These peaks are likely $\delta(\mathrm{CH} 2)$ deformations, although these peaks are normally more prominent in carbohydrates. This peak is more pronounced in the laminarin spectra. This intensity difference is related to the monosaccharide composition of the laminarin and the fucoidan polymer. Unlike glucose, fucose does not contain a hydroymethyl group (-CH2-OH), only a methyl 
group (-CH3). The small, shifted peaks observed in the fucoidan extracts could potentially be from laminarin contamination in the fucoidan extracts. The presence of laminarin was confirmed for all extracts by the $1165 \mathrm{~cm}^{-1}$ band, which we assign to the $\nu(\mathrm{C}-\mathrm{O})$ stretch from glucose.

\section{Raman analysis of fucoidan extracts}

Raman spectrum of the WE exhibits poor signal to noise ratio, likely as a result of melanoidins and potentially other Maillard reaction products. At the first stage of the Maillard reaction, Amadori products are formed. As the Maillard reaction advances, these products may cross-link with adjacent proteins (or other amino groups), creating fluorescent polymeric aggregates, also called advanced glycation end products (AGEs) $[35,36]$ and simultaneously producing melanoidins. Prolonged heating of the extracts is undesirable, as it may result in samples that are unsuitable for Raman spectroscopy. Melanoidins can be converted into fluorescent nanoparticles during heating, which could negatively affect the Raman scattering[37]. Two wavebands, $1004 \mathrm{~cm}^{-1}$ and $1627 \mathrm{~cm}^{-1}$, were very distinct and could hint at the presence of AGEs in the WE. Literature search shows that the $1004 \mathrm{~cm}^{-1}$ band is ring breathing of the amino acid phenylalanine[25, 38], however, glutamic acid (present as glutamate) and aspartic acid make up a noteworthy portion of the total amino acid content in brown algae[39]. One can expect that this peak is due to the ring breathing of an AGE. The band at $1627 \mathrm{~cm}^{-1}$ can be assigned to $\mathrm{v}(\mathrm{C}=\mathrm{O})$, which is characteristic for amides, and to $\mathrm{v}(\mathrm{C}=\mathrm{C})$. We hypothesized that this band can be assigned to melanoidins. Based on the Raman spectra and the size-exclusion chromatography results, it is highly likely that melanoidins are present, however, the presence of AGE could not be definitively confirmed based on the collected data.

The differences between the two acid-based extracts is most apparent in the Raman spectra. These two extracts differ in the wavebands $1054 \mathrm{~cm}^{-1}, 1148 \mathrm{~cm}^{-1}$, $1335 \mathrm{~cm}^{-1}, 1366 \mathrm{~cm}^{-1}$, and $1627 \mathrm{~cm}^{-1}$. These bands are related to carbohydrate stretches. The band at $1054 \mathrm{~cm}^{-1}$ is due to vibrations from $\nu(\mathrm{C}-\mathrm{O}), \nu(\mathrm{C}-\mathrm{C})$ and $\delta(\mathrm{C}-\mathrm{O}-\mathrm{H})$, while the band at $1148 \mathrm{~cm}^{-1}$ is from the stretching of $\nu(\mathrm{C}-\mathrm{O}-\mathrm{C})$ and $\nu(\mathrm{C}-\mathrm{C})$ in glycosidic linkages and asymmetric ring breathing. The waveband 1335 $\mathrm{cm}^{-1}$ is from the stretching and bending of $\nu(\mathrm{C}-\mathrm{O})$ and $\delta(\mathrm{C}-\mathrm{O}-\mathrm{H})$. The band intensities for these stretches are higher for the extract prepared from hydrochloric acid, which indicates that this extract contains more free sugars than the other acid-based extract. The polysaccharides are hydrolyzed to a greater extend when extracted using a traditional extraction solvent. We found four bands that may be indicative of alginate and the intensity of these bands are higher in the hydrochloric acid extract. During extraction, the alginate was likely hydrolyzed and released into the extraction solvent. Gelling of the alginate by addition of calcium chloride solution was insufficient in its removal from the extract, possibly because the alginate fragments in solution had varying gelling properties and could not gel effectively.

We did not find any wavebands related to the $\mathrm{S}=\mathrm{O}$ stretch in Raman, but we assigned the $826 \mathrm{~cm}^{-1}$ waveband to a C-O-S stretch. This peak, along with the $1224 \mathrm{~cm}^{-1}$ peak in infrared, is distorted in the WE. This could indicate that the water extract has less sulfate esters. This was also confirmed by the elemental analysis, although the difference in sulfate ester content is relatively small. The Sigma 


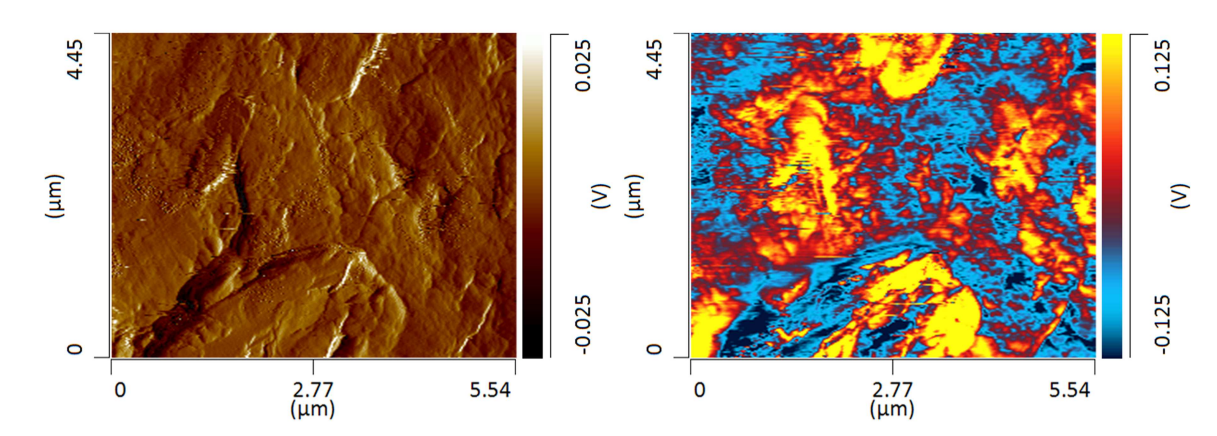

Figure 2 AFM (left) and corresponding AFM-IR (right) maps of the algae (Fucus vesiculosus) frond surface showing topology of the frond (AFM) and distribution of fucoidan $\left(1170 \mathrm{~cm}^{-1}\right)$ in the frond.

standard has a higher sulfate ester content, likely because some of the ester bonds were cleaved during microwaving. Shorter extraction times and lower temperatures conserve the sulfate esters more. The heat stability of the esters is quite high, however, as evidenced in their high occurrence within the acid-based extracts. Sulfation is often reported as a main factor in bioactivity of fucoidans and rapid screening for determination of sulfate esters is highly needed. Raman and IR may provide more rapid screening than elemental analysis, as it measures the $\mathrm{S}=\mathrm{O}$ stretch directly, but since these stretches are also within the region of carbohydrate stretches, it is difficult to make the analysis quantitative. It can be expected that polymer size also affects the position of the $\mathrm{S}=\mathrm{O}$ peaks somewhat. The vibrations of the polymer below $1000 \mathrm{~cm}^{-1}$ depend on all monomeric units, as such, chain length may influence the spectra and may cause the $\mathrm{S}=\mathrm{O}$ peaks to shift.

\section{Nanoscale analysis of fucoidans directly in algae}

The question to ask is whether the structure and composition of fucoidans can be probed directly in algae without their extraction. To answer this question, we used atomic force microscopy Infrared (AFM-IR) spectroscopy. In AFM-IR, the sample surface is illuminated by pulsed tunable IR light that causes thermal expansions of the sample. These thermal expansions are recorded by a metalized AFM tip and converted to IR spectra. The probing depth of AFM-IR is within 100-300 nm, which allows for probing chemical composition of deeper laying material in the sample.

We used AFM-IR to probe distribution of fucoidan in the intact algae (Fucus vesiculosus) frond (Figure 2). For this, we measured change in intensity of the $1170 \mathrm{~cm}^{-1}$ band, which can be assigned to sulfate esters[40, 17], the C-O-C asymmetric stretch of polysaccharides[41], the C-C-O asymmetric stretch for phenols[42], $\mathrm{C}-\mathrm{O}$ stretching of sodium alginate[43], and the polysaccharide backbone[44]. Our results show uneven distribution of fucoidan in the frond with clearly localized island-structures. These findings suggest that AFM-IR may be used for non-invasive screening of potential seaweed candidates for polysaccharide extraction.

\section{Conclusion}

In this paper we investigated the complementarity of Raman and IR spectroscopy to determine the effect of extraction solvents on fucoidan polymer structure. Our 
results show that Raman and IR provide different but complimentary information about crude extracts, particularly revealing how minor impurities from coextractants can be detected without needing destructive and time-consuming analytical techniques. From the IR and Raman spectra, we found that, at high extraction temperatures, acidic conditions limit the formation of melanoidins while also yielding relatively high sulfate ester fucoidan. However, at high temperatures, water extraction may potentially result in the formation of AGEs, which could be problematic for fucoidan extracts intended for medicinal use, as they have been linked to endocrine interruption mechanisms in vivo by crosslinking to and permanently altering extracellular matrix proteins[39].

\section{Materials and methods}

\section{Extraction of fucoidan from Fucus vesiculosus}

For this study, three fucoidan polymers were extracted from Fucus vesiculosus (Biocean, Roscoff, France) using microwave-assisted extraction. The extraction procedure was adapted and modified for microwave-assisted extraction from the method provided by Fletcher et al. (2017)[45]. Extraction was carried out by microwaving at $120^{\circ} \mathrm{C}$ for 30 minutes, using demineralized water, $10 \mathrm{mM} \mathrm{H}_{2} \mathrm{SO}_{4}$, and $100 \mathrm{mM}$ $\mathrm{HCl}$. Once cooled, the extracts were neutralized with $1 \mathrm{M} \mathrm{NaOH}$. For alginate precipitation, a solution of $35 \%$ calcium chloride was added to each extract for a total concentration of $1 \%$. The extracts were then centrifuged $\left(4^{\circ} \mathrm{C}, 30 \mathrm{~min}\right)$ and the supernatant was recovered. Ethanol was added for a concentration of $40 \% \mathrm{v} / \mathrm{v}$ ethanol to precipitate laminarin. The extracts were centrifuged, and the supernatant was recovered. Ethanol was added to give a final concentration of $70 \% \mathrm{v} / \mathrm{v}$ ethanol to precipitate crude fucoidan. The extracts were centrifuged and the crude fucoidan pellet was washed with ethanol and acetone and left to dry to a constant weight. The crude Fucoidan extracts were solubilized in water, dialyzed and lyophilized prior to Raman and IR analysis. For more details, see reference[46]. A fucoidan and a laminarin standard (Sigma Aldrich) were solubilized in demineralized water and used as structural references.

\section{Size-exclusion chromatography}

A standard curve for determination of the molecular weight was prepared by solubilizing pullulan standards (Shodex, Japan) with varying molecular weights (5, 10, 20,50,100, 200,400, $800 \mathrm{kDa}$ ). The pullulan was then filtered and placed into HPLC vials. Size exclusion chromatography was performed on an Ultimate 3000 (Thermofisher, USA) with a refractive index detector. Separation of the standards and samples was achieved on an Agilent BioSEC 3 column (4.5 x 300 mm, $300 \AA$, $3 \mu \mathrm{m} \mathrm{dp})$.

\section{Elemental analysis}

$5 \mathrm{mg}$ of sample was placed into a tin capsule using a pair of tweezers. Using a flat-tipped tweezer, the tin capsule was carefully folded into an airtight, flat square, which was transferred to the sample carrousel of a vario MACRO CUBE (Elementar, Germany) for combustion. The S\% results from the elemental analysis was used to calculate the sulfate ester content via Eq. 1 


\section{Raman and Infrared spectroscopy}

Raman spectra of the extracts were collected using a hand-held Resolve Agilent spectrometer equipped with $831 \mathrm{~nm}$ laser source. The following experimental parameters were used for all collected spectra: 1s acquisition time, $495 \mathrm{~mW}$ power, and baseline spectral subtraction by the device software. FT-IR spectra were acquired on Perkin Elmer 100 spectrometer equipped with attenuated total reflectance (ATR) module. Spectra were recorded with a resolution of $4 \mathrm{~cm}^{-1}$ in the range of 4000-560 $\mathrm{cm}^{-1}$. A background spectrum was acquired immediately before the measurement.

\section{Screening of seaweed surface by AFM-IR}

AFM-IR imaging was conducted using a Nano-IR3 system (Bruker, Santa Barbara, USA). The IR source was a QCL laser. Contact mode AFM tips (Anasys Instruments Inc., Santa Barbara, USA) with a resonance frequency of $13 \pm 4 \mathrm{kHz}$ and a spring con-stant of $0.007-0.4 \mathrm{~N} / \mathrm{m}$ were used to obtain all spectra and maps.

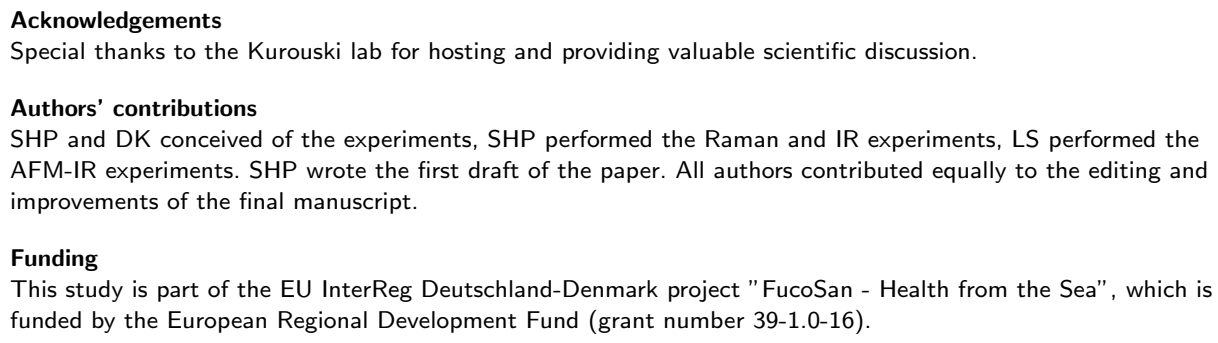

1. Takahashi, H., Kawaguchi, M., Kitamura, K., Narumiya, S., Kawamura, M., Tengan, I., Nishimoto, S., Hanamure, Y., Majima, Y., Tsubura, S., Teruya, K., Shirahata, S.: An Exploratory Study on the Anti-inflammatory Effects of Fucoidan in Relation to Quality of Life in Advanced Cancer Patients. Integrative Cancer Therapies 17(2), 282-291 (2018). doi:10.1177/1534735417692097

2. Cho, M.L., Lee, B.Y., You, S.: Relationship between oversulfation and conformation of low and high molecular weight fucoidans and evaluation of their in vitro anticancer activity. Molecules 16(1), 291-297 (2011). doi:10.3390/molecules 16010291

3. Ale, M.T., Maruyama, H., Tamauchi, H., Mikkelsen, J.D., Meyer, A.S.: Fucose-containing sulfated polysaccharides from brown seaweeds inhibit proliferation of melanoma cells and induce apoptosis by activation of caspase-3 in vitro. Marine Drugs 9(12), 2605-2621 (2011). doi:10.3390/md9122605

4. Chaminda Lakmal, H.H., Samarakoon, K.W., Jeon, Y.J.: Enzyme-Assisted Extraction to Prepare Bioactive Peptides from Microalgae. Marine Algae Extracts: Processes, Products, and Applications 1-2, 305-318 (2015). doi:10.1002/9783527679577.ch18 
5. Rodriguez-Jasso, R.M., Mussatto, S.I., Pastrana, L., Aguilar, C.N., Teixeira, J.A.: Microwave-assisted extraction of sulfated polysaccharides (fucoidan) from brown seaweed. Carbohydrate Polymers 86, 1137-1144 (2011). doi:10.1016/j.carbpol.2011.06.006

6. Yuan, Y., Macquarrie, D.: Microwave assisted extraction of sulfated polysaccharides (fucoidan) from Ascophyllum nodosum and its antioxidant activity. Carbohydrate Polymers 129, 101-107 (2015). doi:10.1016/j.carbpol.2015.04.057

7. Geng, L., Zhang, Q., Wang, J., Jin, W., Zhao, T., Hu, W.: Glucofucogalactan, a heterogeneous low-sulfated polysaccharide from Saccharina japonica and its bioactivity. International Journal of Biological Macromolecules 113, 90-97 (2018). doi:10.1016/j.ijbiomac.2018.02.008

8. Álvarez-Viñas, M., Flórez-Fernández, N., González-Muñoz, M.J., Domínguez, H.: Influence of molecular weight on the properties of Sargassum muticum fucoidan. Algal Research 38(September 2018), 101393 (2019). doi:10.1016/j.algal.2018.101393

9. Cumashi, A., Ushakova, N.A., Preobrazhenskaya, M.E., D'Incecco, A., Piccoli, A., Totani, L., Tinari, N., Morozevich, G.E., Berman, A.E., Bilan, M.I., Usov, A.I., Ustyuzhanina, N.E., Grachev, A.A., Sanderson, C.J., Kelly, M., Rabinovich, G.A., lacobelli, S., Nifantiev, N.E.: A comparative study of the anti-inflammatory, anticoagulant, antiangiogenic, and antiadhesive activities of nine different fucoidans from brown seaweeds. Glycobiology 17(5), 541-552 (2007). doi:10.1093/glycob/cwm014

10. Wei, X., Cai, L., Liu, H., Tu, H., Xu, X., Zhou, F., Zhang, L.: Chain conformation and biological activities of hyperbranched fucoidan derived from brown algae and its desulfated derivative. Carbohydrate Polymers 208(December 2018), 86-96 (2019). doi:10.1016/j.carbpol.2018.12.060

11. Clément, M.-J., Tissot, B., Chevolot, L., Adjadj, E., Du, Y., Curmi, P.A., Daniel, R.: NMR characterization and molecular modeling of fucoidan showing the importance of oligosaccharide branching in its anticomplementary activity. Glycobiology 20(7), 883-894 (2010). doi:10.1093/glycob/cwq046

12. Wu, H., Gao, S., Terakawa, S.: Inhibitory effects of fucoidan on NMDA receptors and I-type Ca $2+$ channels regulating the $\mathrm{Ca} 2+$ responses in rat neurons. Pharmaceutical biology 57(1), 1-7 (2019). doi:10.1080/13880209.2018.1548626

13. Wiercigroch, E., Szafraniec, E., Czamara, K., Pacia, M.Z., Majzner, K., Kochan, K., Kaczor, A., Baranska, M., Malek, K.: Raman and infrared spectroscopy of carbohydrates: A review. Spectrochimica Acta - Part A: Molecular and Biomolecular Spectroscopy 185(May), 317-335 (2017). doi:10.1016/j.saa.2017.05.045

14. Almeida, M.R., Alves, R.S., Nascimbem, L.B.L.R., Stephani, R., Poppi, R.J., De Oliveira, L.F.C.: Determination of amylose content in starch using Raman spectroscopy and multivariate calibration analysis. Analytical and Bioanalytical Chemistry 397(7), 2693-2701 (2010). doi:10.1007/s00216-010-3566-2

15. George Socrates: Infrared and Raman Characteristic Group Frequencies Contents, Third ed. edn., p. 347. John Wiley \& Sons, Chichester, England (2001)

16. Hellebust, J.A., Craigie, J.S. (eds.): Handbook of Phycological Methods, 2nd edn. Cambridge University Press, Cambridge (1978)

17. Mathlouthi, M., Koenig, J.L.: Vibrational spectra of carbohydrates. Advances in Carbohydrate Chemistry and Biochemistry 44(C), 7-89 (1987). doi:10.1016/S0065-2318(08)60077-3

18. Stuart Tipson, R.: Infrared Spectroscopy Of Carbohydrates: A Review of the Literature, p. 38. DEPARTMENT OF COMMERCE NATIONAL BUREAU OF STANDARDS, (1968)

19. Onodera, K., Hirang, S., Kashimura, N.: Infrared Spectra of the Sulfonic Esters of Monosaccharide. Carbohydrate Research 1(3), 208-213 (1965)

20. Campos-Vallette, M.M., Chandía, N.P., Clavijo, E., Leal, D., Matsuhiro, B., Osorio-Román, I.O., Torres, S.: Characterization of sodium alginate and its block fractions by surface-enhanced raman spectroscopy. Journal of Raman Spectroscopy 41(7), 758-763 (2010)

21. Adar, F.: Carotenoids - Their Resonance Raman Spectra and How They Can Be Helpful in Characterizing a Number of Biological Systems. Spectroscopy 2(June) (2017)

22. Liu, L.-S., Ballada, A., Zaikov, G.E., Haghi, A.K. (eds.): Engineering of Polymers and Chemical Complexity, Volume I: Current State of the Art and Perspectives, p. 481. Apple Academic Press, Toronto (2014)

23. Ismail Hakki Boyaci, A., Tümay Temiz, H., Efe Geniș, H., Acar Soykut, E., Nur Yazgan, N., Güven, B., Selin Uysal, R., Göktuğ Bozkurt, A., Ä laslan, K., Torun, O., Ceyda Dudak Șeker, F., HakkÄ \pm BoyacÄ \pm , Ä.: Supplementary data for Dispersive and FT-Raman Spectroscopic Methods in Food Analysis. RSC advances $\mathbf{5}$, 1-62 (2015)

24. Agarwal, S.K.D., Johary, P.C., Misra, D.S.: Infrared Spectroscopic Studies on Different Colorants as Obtained by Paper Chromatographic Elution and on Dialysis. Z. Ver. Dtsch. Zucker Ind. (24), 532-535 (1974)

25. De Gelder, J., De Gussem, K., Vandenabeele, P., Moens, L.: Reference database of Raman spectra of biological molecules. Journal of Raman Spectroscopy 38(April), 1133-1147 (2007). doi:10.1002/jrs

26. Baujard-Lamotte, L., Noinville, S., Goubard, F., Marque, P., Pauthe, E.: Kinetics of conformational changes of fibronectin adsorbed onto model surfaces. Colloids and Surfaces B: Biointerfaces 63(1), 129-137 (2008). doi:10.1016/j.colsurfb.2007.11.015

27. Ma, C.Y., Rout, M.K., Mock, W.Y.: Study of oat globulin conformation by Fourier transform infrared spectroscopy. Journal of Agricultural and Food Chemistry 49(7), 3328-3334 (2001). doi:10.1021/jf010053f

28. Lin-Vien, D., Colthup, N., Fateley, W., Grasselli, J.: The Handbook of Infrared and Raman Characteristic Frequencies of Organic Molecules. Academic Press, San Diego, CA (1991)

29. Ale, M.T., Mikkelsen, J.D., Meyer, A.S.: Important determinants for fucoidan bioactivity: A critical review of structure-function relations and extraction methods for fucose-containing sulfated polysaccharides from brown seaweeds (2011). doi:10.3390/md9102106

30. Zvyagintseva, T.N., Shevchenko, N.M., Popivnich, I.B., Isakov, V.V., Scobun, A.S., Sundukova, E.V., Elyakova L.A.: A new procedure for the separation of water-soluble polysaccharides from brown seaweeds. Carbohydrate Research 322(1-2), 32-39 (1999). doi:10.1016/S0008-6215(99)00206-2

31. Grachev, A., Gerbst, A., Ustyuzhanina, N., Shashkov, A., Usov, A., Nifantiev, N.: NMR investigation of the influence of sulfate groups at C-2 and C-4 on the conformational behavior of fucoidan fragments with 
homo-(1-3)-linked backbone. Journal of Carbohydrate Chemistry 25(4), 315-330 (2006) doi:10.1080/07328300600770493

32. Li, B., Lu, F., Wei, X., Zhao, R.: Fucoidan: Structure and bioactivity. Molecules 13, 1671-1695 (2008). doi:10.3390/molecules13081671

33. Cämmerer, B., Kroh, L.W.: Investigation of the influence of reaction conditions on the elementary composition of melanoidins. Food Chemistry 53(1), 55-59 (1995). doi:10.1016/0308-8146(95)95786-6

34. Mohsin, G.F., Schmitt, F.J., Kanzler, C., Dirk Epping, J., Flemig, S., Hornemann, A.: Structural characterization of melanoidin formed from D-glucose and L-alanine at different temperatures applying FTIR, NMR, EPR, and MALDI-ToF-MS. Food Chemistry 245(December 2017), 761-767 (2018). doi:10.1016/j.foodchem.2017.11.115

35. Bosch, L., Alegría, A., Farre, R., Clemente Marín, G.: Fluorescence and colour as markers for the Maillard reaction in milk-cereal based infants foods during storage. Food Chemistry. Food Chemistry 105(3), 1135-1143 (2007). doi:10.1016/j.foodchem.2007.02.016

36. Ravichandran, G., Lakshmanan, D.K., Raju, K., Elangovan, A., Nambirajan, G., Devanesan, A.A., Thilagar, S.: Food advanced glycation end products as potential endocrine disruptors: An emerging threat to contemporary and future generation. Environment International 123(October 2018), 486-500 (2019). doi:10.1016/j.envint.2018.12.032

37. Li, D., Xie, Y., Na, X., Li, Y., Dai, C., Li, Y., Tan, M.: Insights of melanoidin conversion into fluorescent nanoparticles in the Maillard reaction. Food \& Function, 1-10 (2019). doi:10.1039/C9FO00383E

38. Rygula, A., Majzner, K., Marzec, K.M., Kaczor, A., Pilarczyk, M., Baranska, M.: Raman spectroscopy of proteins: A review. Journal of Raman Spectroscopy 44(8), 1061-1076 (2013). doi:10.1002/jrs.4335

39. MacArtain, P., Gill, C.I.R., Brooks, M., Campbell, R., Rowland, I.R.: Nutritional Value of Edible Seaweeds. Nutrition Reviews 65(12), 535-543 (2007). doi:10.1301/nr.2007.dec.535

40. Robinson, E.: Characteristic vibrations of the sulphuryl group. Canadian Journal of Chemistry 39(1), 247-255 (1961)

41. Cui, W., Kamdem, D.P., Rypstra, T.: Diffuse reflectance infrared fourier transform spectroscopy (drift) and color changes of artificial weathered wood. Wood and Fiber Science 36(3), 291-301 (2007)

42. Poljansek, I., Krajnc, M.: Characterization of phenol-formaldehyde prepolymer resins by in line $\mathrm{ft}$-ir spectroscopy. Acta Chimica Slovenica 52(3), 238 (2005)

43. Murillo-Álvarez, J.I., Hernández-Carmona, G.: Monomer composition and sequence of sodium alginate extracted at pilot plant scale from three commercially important seaweeds from mexico. Journal of applied phycology 19(5), 545-548 (2007)

44. Kačuráková, M., Wilson, R.: Developments in mid-infrared ft-ir spectroscopy of selected carbohydrates. Carbohydrate polymers 44(4), 291-303 (2001)

45. Fletcher, H.R., Biller, P., Ross, A.B., Adams, J.M.M.: The seasonal variation of fucoidan within three species of brown macroalgae. Algal Research 22, 79-86 (2017). doi:10.1016/j.algal.2016.10.015

46. Ptak, S.H., Christensen, K.V., Meichßner, R., Fretté, X.: Improving fucoidan yield from fucus brown algae by microwave extraction. Chemical Engineering Transactions 74 (2019) 
Figures
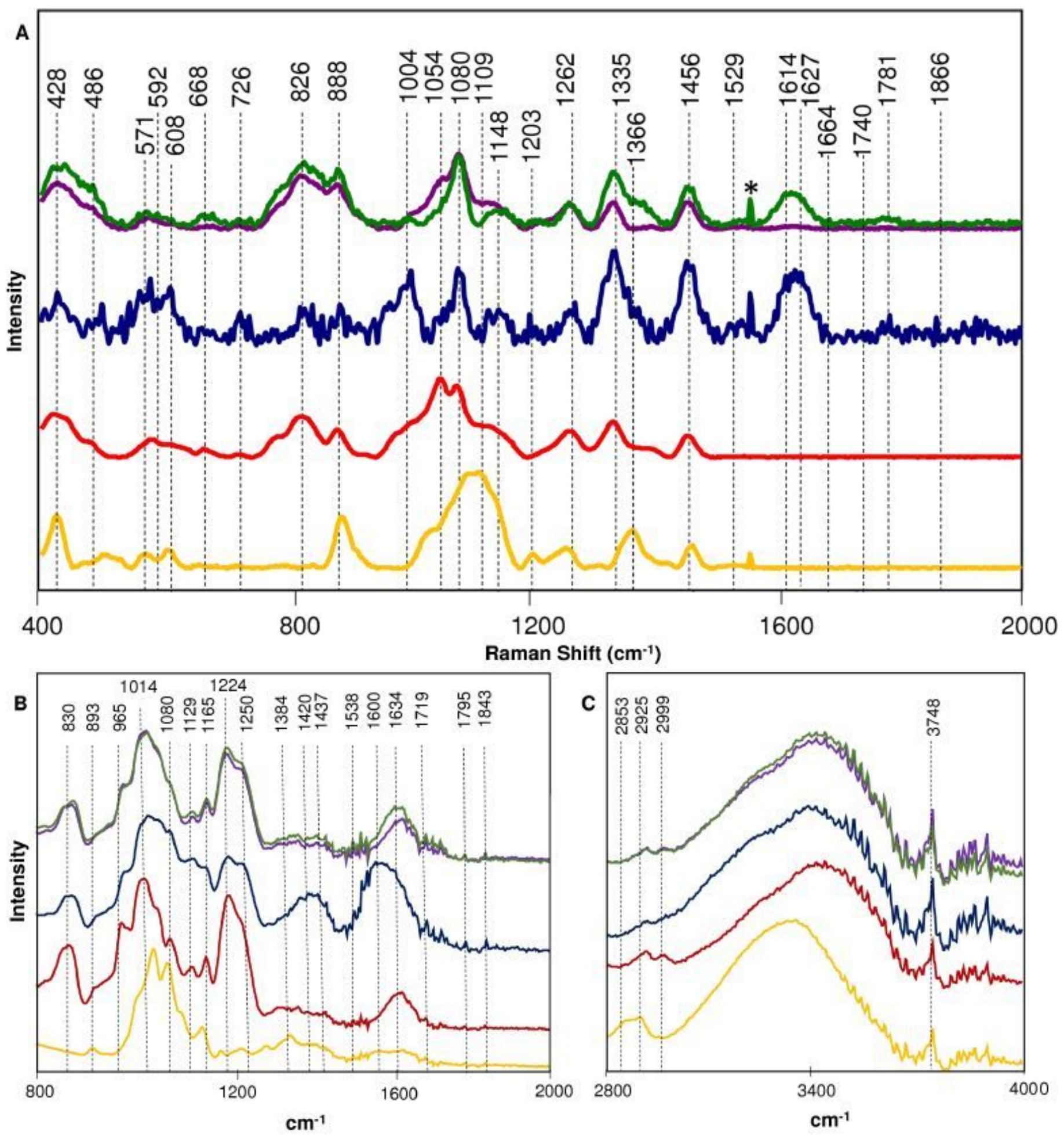

Figure 1

Raman (A) and infrared (B) and C) spectra of fucoidan extracts. The purple spectrum indicates fucoidan extraction with $10 \mathrm{mM} \mathrm{H} 2 \mathrm{SO}$, while green and blue is $100 \mathrm{mM} \mathrm{HCl}$ and pure water, respectively. Red shows the reference fucoidan and yellow the laminarin reference sample. 

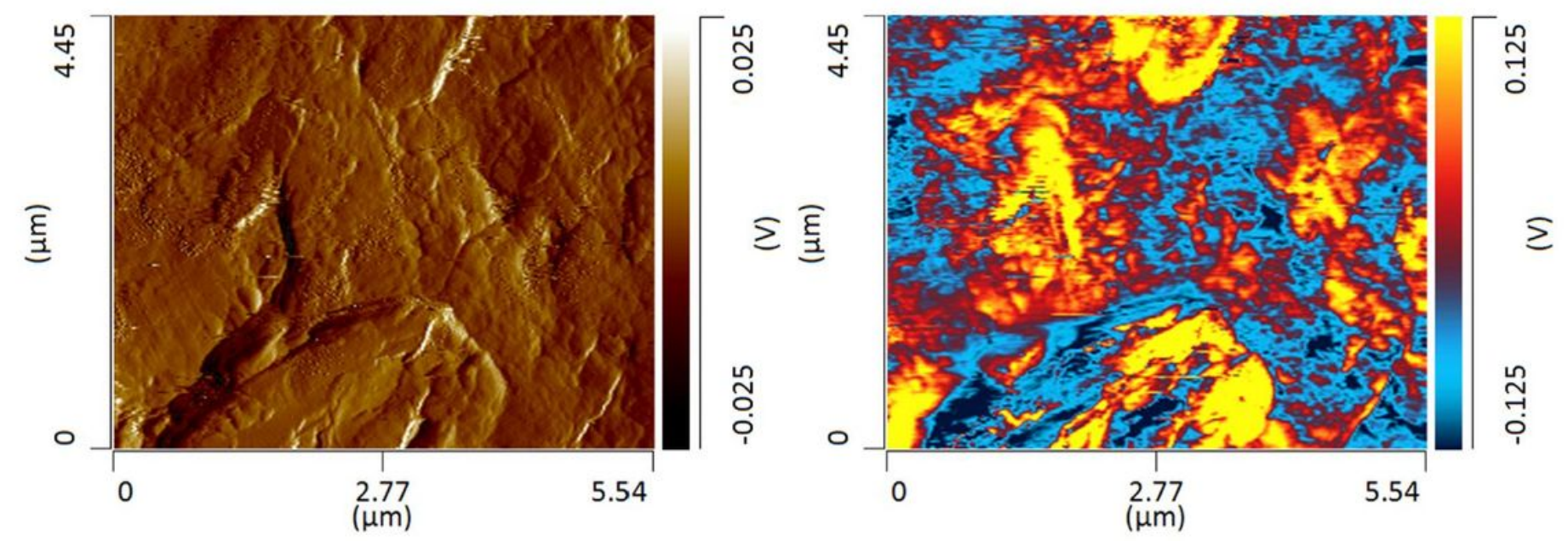

Figure 2

AFM (left) and corresponding AFM-IR (right) maps of the algae (Fucus vesiculosus) frond surface showing topology of the frond (AFM) and distribution of fucoidan $(1170 \mathrm{~cm}-1)$ in the frond.

\section{Supplementary Files}

This is a list of supplementary files associated with this preprint. Click to download.

- Ramancombinedv3.png

- AFMIR.png 